\title{
The application of the theory of planned behavior to nutritional behaviors related to cardiovascular disease among the women
}

\author{
Ali Khani Jeihooni ${ }^{1,7^{*}}$, Hanieh Jormand ${ }^{2}$, Negin Saadat ${ }^{3}$, Mahmood Hatami ${ }^{4}$, Rosliza Abdul Manaf and \\ Pooyan Afzali Harsini ${ }^{6}$
}

\begin{abstract}
Background: Nutritional factors have been identified as preventable risk factors for cardiovascular disease; this study aimed to investigate the application of the Theory of Planned Behavior (TPB) in nutritional behaviors related to cardiovascular diseases among the women in Fasa city, Fars province, Iran.

Methods: The study was conducted in two stages. First, the factors affecting nutritional behaviors associated with cardiovascular disease on 350 women who were referred to Fasa urban health centers were determined based on the TPB. In the second stage, based on the results of a cross-sectional study, quasi-expeimental study was performed on 200 women covered by Fasa health centers. The questionnaire used for the study was a questionnaire based on TPB. The questionnaire was completed by the experimental and control groups before and three months after the intervention. Data were analyzed by SPSS software using logistic regression, paired t-test, independent sample t-test, and chi-square test. The level of significance is considered 0.05 .
\end{abstract}

Result: The constructs of attitude, subjective norms, and perceived behavioral control (PBC) were predictors of nutritional behaviors associated with cardiovascular disease in women. The constructs predicted $41.6 \%$ of the behavior. The results showed that mean scores of attitude, subjective norms, PBC, intention, nutritional performance related to the cardiovascular disease before intervention were, respectively, 24.32, 14.20, 18.10, 13.37 and 16.28, and after the intervention, were, respectively, 42.32, 25.40, 33.72, 30.13 and 41.38. All the constructs except the attitude in the intervention group were significantly higher $(p<0.001)$ than the control group.

Conclusion: The results of the present study showed that the educational intervention based on the TPB would be consider an effective educational and promotinal strategy for the nutritional behaviors to prevent cardiovascular disease in women. Considering the role of mothers in providing family food baskets and the effect of their nutritional behaviors on family members, the education of this group can promote healthy eating behaviors in the community and family.

Keywords: Cardiovascular disease, Nutritional behaviors, Theory of planned behavior, Educational intervention

*Correspondence: khani_1512@yahoo.com

${ }^{1}$ Nutrition Research Center, Department of Public Health, School

of Health, Shiraz University of Medical Sciences, Shiraz, Iran

Full list of author information is available at the end of the article

\section{Background}

A cardiovascular disease is a group of non-communicable diseases that is the main cause of death worldwide with an estimated 17.5 million deaths annually $[1,2]$. Cardiovascular disease (CVD) would be the cause of more than 23 million (about 30.5\%) deaths by 2030 worldwide [1, 
3 , 4]. These diseases can lead to hospitalization, disability, and a decline in quality of life [5]. Also, the economic burden of cardiovascular disease is high, so that in the United States in 2010, approximately $\$ 315$ million was spent on this disease and is estimated to rise to $\$ 818$ billion by 2030 [6, 7].

Cardiovascular disease is generally thought to affect men more than women, while it is not true [8]. According to the statistics, when a heart attack occurs, women die twice as much as men in the first week, and the death rate in women, 1 year after a heart attack, is $13 \%$ higher than men [9]. Tobacco use, inactivity, hypertension, hyperlipidemia, diabetes, obesity, and overweight, stress, contraceptives, and alcohol use are risk factors for cardiovascular disease [10-12]. CVD can be prevented by modifying risk factors and increasing knowledge [13, 14]. To adopt healthy behaviors, people must be aware of the disease and, considering themselves susceptible to the disease, believe that they can prevent or cure the disease [15]. Nutritional factors have been identified as preventable risk factors for cardiovascular disease [16]. Most of the major risk factors for cardiovascular disease, including hyperlipidemia, hypertension, obesity, and diabetes are related to inappropriate eating habits [17]. Increasing consumption of foods high in saturated fat with high calories and reducing consumption of complex carbohydrates, dietary fiber, fruits, and vegetables have a significant impact on controllable risk factors for cardiovascular disease [18]. Studies have shown that the diet of $73 \%$ of Iranians needs to change [19].

Health educators play an important role in training the population to adopt healthy behaviors and learn the risk factors and diseases [20]. To change behavior, health educators need to have a good understanding of the health and social characteristics, beliefs, attitudes, values, skills, and past behaviors of individuals [21]. Although the change of behavior is very challenging, considering a behavioral model will help to change one's beliefs about cardiovascular disease [22]. Evidence demonstrated several important factors that could predict and affect food behaviors in women such as knowledge, self-regulation, outcome expectations, outcome expectancies [23], attitude, subjective norms, $\mathrm{PBC}$, and intention [24].

TPB is a social-cognitive theory that provides a useful framework for predicting and understanding healthrelated behaviors $[20,25]$. According to this theory, the intention is the primary determinant of behavior. The intention of the individual is influenced by the three factors of attitude, subjective norms, and PBC [26, 27] Conceptual framework of TPB is presented in Fig. 1.

The theory is one of the important models in food selection [28-30]. In a study by Emanuel et al., the application of the TPB to the consumption of fruits and vegetables

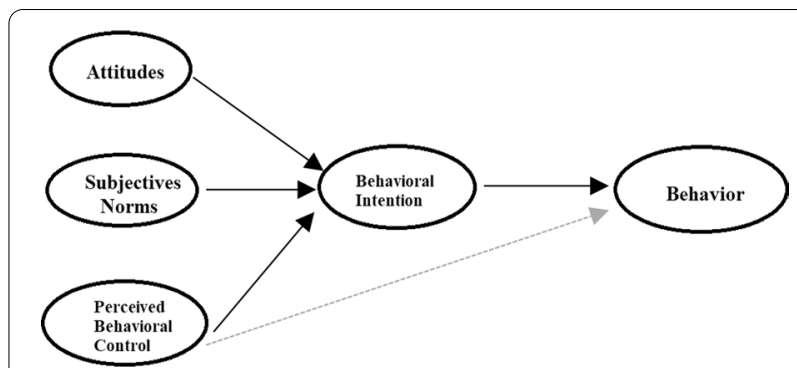

Fig. 1 Theory of planned behavior (TPB)

was examined. The results showed that women had better-perceived attitudes and behaviors than men about fruits and vegetables, while men were more abstract [31]. Blanchard et al. investigated the application of the TPB to the consumption of fruits and vegetables 5 times a day among college students and examined that does gender or ethnicity affects this behavior. The results of the study showed that the TPB is a useful framework for intervening in the consumption of fruits and vegetables 5 times a day in men and women of different ethnicities and is not affected by gender and ethnicity [32]. Also, the results of the study by Gholami et al. showed that attitudes, habits, and tendencies have a direct impact on fruit and vegetable consumption. In general, the TPB can help predict and plan healthy behaviors and disease prevention [33]. A study by Hyun-sun Seo et al. investigated the application of TPB to the factors influencing fast food consumption among high school students in Seoul. The study showed that most students consume fast food under the influence of their friends as well as on special occasions and that girls are more interested in maintaining health and weight control than boys. The TPB indicated that fast food consumption was significantly influenced by behavioral tendencies [34]. Yarmohammadi et al. showed that the TPB provided a good predictor of the tendency to fast food consumption but is not very helpful in predicting behavior [35]. Rezabeigi Davarani et al. investigated the application of the TPB in predicting the factors affecting nutritional behaviors associated with cardiovascular disease among health volunteers in Kerman. This study showed that PBC is a strong predictor of food intentions and behaviors [24].

Consequently, considering the role of mothers in providing family food baskets and the effect of their nutritional behaviors on family members, the education of women can promote healthy eating behaviors in the community and family.

On the other hand, Given that understanding the factors affecting nutritional behavior and performing educational interventions will be of great help in preventing 
cardiovascular disease, especially among women, this study aimed to investigate the application of the TPB in nutritional behaviors related to cardiovascular diseases among the women in Fasa city, Fars province, Iran.

\section{Methods}

\section{First stage study design}

The study was conducted in two stages. First stage, the factors affecting nutritional behaviors associated with cardiovascular disease on 350 women who were referred to Fasa urban health centers were selected to determine the important factors affecting this behavior based on the TPB. This study was performed in January 2018- April 2019.

\section{First stage sample size and setting}

This sample size was estimated based on Vahdani et al. [36] and Rezabeigi Davarani [24] with 350 individuals considering $\alpha=5 \%, \beta=20 \%$, and sample loss.

$$
n=\frac{z^{2} s^{2}}{d^{2}}=\frac{(1.96)^{2} \times(0.47)^{2}}{(0.05)^{2}}=\frac{(3.84)(0.226)}{0.0025} \cong 350
$$

The study population consisted of women referred to Fasa health centers. After obtaining the necessary permits from Fasa University of Medical Sciences and Fasa Health Center, referring to selected centers (out of 6 Fasa Health Centers, 2 centers were randomly selected), availability sampling was performed from the women who visited the centers and had a family file. Then, by selecting each sample, the researcher introducing himself and stating the purpose of the study emphasized the confidentiality of the information. Finally, the questionnaires were completed by the patients. The inclusion criteria of the study were the willingness to participate, $20-50$ years of age, and no pregnancy. Exclusion criteria included the unwillingness to participate and a history of cardiovascular disease.

\section{First stage statistical analyses}

Data were analyzed by SPSS software with using logistic regression analysis. The significance level was considered 0.05 .

\section{Second stage study design and setting}

In the second stage, based on the results of a cross-sectional study, quasi-expeimental study was performed on 200 women covered by Fasa health centers in May 2019September 2019. Out of 6 Fasa health centers, 2 centers were randomly selected (100 as the experimental group and 100 as the control group). Inclusion criteria included the willingness to participate, ages $20-50$, and no pregnancy. Exclusion criteria included cardiovascular disease, unwillingness to continue the study, and absence for more than two educational sessions.

\section{Interventional program}

The educational intervention for the experimental group consisted of eight 50-55 min' sessions on the lecture, group discussion, question and answer, use of video and instructional images, and PowerPoint presentations. The educational program was performed by a Ph.D. expert in health education and health promotion with the collaboration of a nutritionist. The content of the educational sessions was the concepts related to the cardiovascular disease preventive diet. The details of the training sessions are presented in Table 1.

\section{Interventional procedure}

Educational sessions were held for 4 groups of 25 patients (of experimental group) weekly in the health center. A WhatsApp group was formed to exchange information and send motivational and educational messages every 5 days. Two follow-up sessions were held 1 month later and 2 months after the intervention to review the material.

For ethical considerations, the study was approved by the Ethics Committee of Fasa University of Medical Sciences. Completing informed consent by the participants, the goals, importance, necessity of the study were discussed, and the participants were assured that their information would be treated completely confidential. Both experimental and control groups have participated from the beginning to the end of the study. The control group did not receive any educational program except that they were just invited to complete the questionnaire. To adhere to ethical standards, an educational session was held for the control group at the end of the study.

\section{Second stage study instrument}

The tool used for the study was a questionnaire prepared based on former studies [24, 36-39]. The questionnaire consisted of 50 questions in 2 sections. The first section included demographic information (age, weight, height, household size, education, marital status, occupation, household income, family history of cardiovascular disease, history of tobacco use, and history of cardiovascular-related education). The second part included the constructs of the TPB such as attitude (positive and negative assessment of behavior), subjective norms, PBC, intention, and nutritional behavior that were designed and regulated by the researcher through the study of books, papers, and literature.

To measure attitude, subjective norms, and PBC, Likert scale ranging from 1 (strongly disagree) to 5 (strongly agree) was used: 10 items were used to measure attitude, 
Table 1 The details of the training sessions

\begin{tabular}{|c|c|c|c|}
\hline Sessions & Contents & Constructs & Presentations \\
\hline First session & $\begin{array}{l}\text { Introduction to cardiovascular disease and its } \\
\text { symptoms, complications and diagnosis }\end{array}$ & Attitude & $\begin{array}{l}\text { Lecture- group discussion- question and } \\
\text { answer-use of video }\end{array}$ \\
\hline Second session & $\begin{array}{l}\text { A 55-year-old woman diagnosed with } \\
\text { cardiovascular disease was invited as a model } \\
\text { and talked to the subjects about cardiovas- } \\
\text { cular diseases and its risk factors, symptoms, } \\
\text { complications, and diagnosis with the help of } \\
\text { a physician }\end{array}$ & Attitude-Subjective norms & $\begin{array}{l}\text { Role playing- group discussion- use of video } \\
\text { and instructional images- }\end{array}$ \\
\hline Third and fourth sessions & $\begin{array}{l}\text { The role of nutrition in preventing cardiovas- } \\
\text { cular disease, benefits and barriers of diet, fol- } \\
\text { lowing dietary recommendations, perceived } \\
\text { behavioral control in observing proper diet, } \\
\text { and recording activities in the specified forms }\end{array}$ & $\begin{array}{l}\text { Perceived behavioral con- } \\
\text { trol- Attitude-Nutritional } \\
\text { performance }\end{array}$ & $\begin{array}{l}\text { group discussion- question and answer-use of } \\
\text { instructional images- PowerPoint }\end{array}$ \\
\hline Fifth and sixth sessions & $\begin{array}{l}\text { two sessions was held with the presence of } \\
\text { at least one family member and the role of } \\
\text { family members in making, facilitating, and } \\
\text { providing suitable food was explained }\end{array}$ & Subjective norms-Intention & $\begin{array}{l}\text { Lecture-group discussion- question and } \\
\text { answer-PowerPoint }\end{array}$ \\
\hline Seventh session & $\begin{array}{l}\text { Nutritional behavior preventing cardiovas- } \\
\text { cular disease -type and composition and } \\
\text { amount of food, fruits and vegetables, etc } \\
\text { Intention to consume proper nutrition }\end{array}$ & $\begin{array}{l}\text { Intention- Nutritional } \\
\text { performance- Perceived } \\
\text { behavioral control }\end{array}$ & $\begin{array}{l}\text { use of video and instructional images- Pow- } \\
\text { erPoint }\end{array}$ \\
\hline Eighth session & $\begin{array}{l}\text { The previous sessions were reviewed and } \\
\text { the subjects were provided with educational } \\
\text { pamphlets }\end{array}$ & All constructs & Educational booklet- WhatsApp group \\
\hline
\end{tabular}

for example, 'I prefer to eat boiled food' and 'I think we should eat fruits and vegetables every day'; 6 items were used to measure subjective norms such as 'My family members are interested that I cook foods according to the appropriate principles of nutrition' and 'Health workers encourage me to follow healthy diet'; 8 questions were asked to assess PBC, for example, 'I can choose healthy food even if it doesn't taste delicious' and 'I can avoid the conditions that tempt me to eat unhealthy food; 7 behavioral intention questions were also scored on a five-point Likert scale ranging from very low to very high, such as 'I intend to include at least 3 to 5 servings of vegetables and fruits a day' and 'I intend to incorporate fish 1 to 2 times a week into the diet'; and performance including 10 questions such as 'I consume at least three fruits a day' and 'I put salt on the table when eating' was measured on a Likert scale ranging from 1 to 5 .

The validity of the items was evaluated by calculating the item impact score above 0.15 and the content validity ratio higher than 0.79 . To determine the tool's face validity, a list of compiled items targeted by 30 women with similar demographic, economic, and social characteristics. To determine the content validity, the opinions of 12 experts (outside the research team) on health education and health promotion $(\mathrm{n}=10)$, nutritionist $(\mathrm{n}=1)$, and cardiologist $(\mathrm{n}=1)$ were used. Using the Lawshe table index, the item which was 0.56 larger for 12 subjects, was considered essential and kept for further analysis.
The overall reliability of the tool with Cronbach's alpha was 0.88 . The construct validity of attitude was 0.84 , PBC 0.82 , abstract norms 0.89 , behavioral intention 0.87 , and performance 0.86 . Also, Participants' height was measured using standing tape on the wall without shoes and weight with the minimum coverage and without shoes using digital scales. Finally, Body Mass Index (BMI) was calculated by SPSS software. Body mass index less than 18.5 was considered to be lean, 18.5-24.9 normal, 25.99.9 overweight, and 30 and above obese. The questionnaire was completed by the experimental and control groups before and three months after the intervention.

\section{Second stage study statistical analyses}

Data of the second study were analyzed by SPSS 22 software The data in before analysis was the normal distribution. Demographic variables were compared between two groups with the Chi-square test. Comparison between the constructs of TPB and jogging performance was done with Paired t-test in groups. Constructs of TPB and jogging performance were also compared between two groups with an independent $t$-test. The level of significance is considered $<0.05$.

\section{Findings}

In the cross-sectional study, 350 women with the mean $( \pm$ SD) age of $39.58 \pm 4.86$ years participated in the study. The results of the logistic regression analysis to predict 
nutritional behaviors related to cardiovascular disease based on the TPB are presented in Table 2. According to the results, all three constructs of attitude, subjective norms, and $\mathrm{PBC}$ were predictors of nutritional behaviors associated with cardiovascular disease in women. Generally, all the studied variables, predicted of the behavior ( $\mathrm{R}^{2}$ Adjusted $=0.28$ ).

In the quasi-experimental study, the mean $( \pm S D)$ age of women in the experimental group was $38.80 \pm 4.75$ and in the control group $39.25 \pm 4.20$ years $(p=0.194)$. Besides, the mean household size in the experimental group was $3.88 \pm 2.68$ and in the control group
$3.74 \pm 2.72(p=0.221)$, in which there was no significant difference between the two groups. The results of the interventional study indicated that the chi-square test showed a significant difference between the experimental and control groups in terms of occupation variables, household income, education level, marital status, BMI, family history of cardiovascular disease, and history of receiving cardiovascular education, and history of tobacco use (Table 3).

The results showed that there was no significant difference between the experimental and control groups regarding attitude, subjective norms, $\mathrm{PBC}$, intention,

Table 2 Linear regression analysis of the factors related to nutritional behaviors associated with cardiovascular disease in women $(\mathrm{N}=350)$

\begin{tabular}{lllll}
\hline Variables & Beta & STD $\boldsymbol{\beta}$ & $\boldsymbol{p}$ & Dependent variable \\
\hline Attitude & 0.179 & 0.111 & 0.034 & Nutritional behaviors associated with cardiovascular disease \\
Perceived behavioral control & 0.272 & 0.071 & 0.014 & $\mathrm{R}^{2}=0.416$ \\
Subjective norms & 0.182 & 0.102 & 0.018 & $\mathrm{R}^{2}$ Adjusted $=0.28$ \\
\hline
\end{tabular}

Table 3 Comparison of demographic variables of studied patients in two groups of experimental and control

\begin{tabular}{|c|c|c|c|c|c|c|}
\hline \multirow[t]{2}{*}{ Variables } & & \multicolumn{2}{|c|}{ Experimental group } & \multicolumn{2}{|c|}{ Control group } & \multirow[t]{2}{*}{$P$-value* } \\
\hline & & Percentage & Number & Percentage & Number & \\
\hline \multirow[t]{4}{*}{ Marital status } & Single & 9 & 9 & 7 & 7 & \multirow[t]{4}{*}{0.317} \\
\hline & Married & 81 & 81 & 85 & 85 & \\
\hline & Divorced & 4 & 4 & 5 & 5 & \\
\hline & Widowed & 6 & 6 & 3 & 3 & \\
\hline \multirow[t]{5}{*}{ Education level } & Illiterate & 1 & 1 & 0 & 0 & \multirow[t]{5}{*}{0.262} \\
\hline & Primary school & 7 & 7 & 6 & 6 & \\
\hline & Secondary school & 28 & 28 & 32 & 32 & \\
\hline & High school & 44 & 44 & 46 & 46 & \\
\hline & College & 20 & 20 & 16 & 16 & \\
\hline \multirow[t]{3}{*}{ Monthly income } & Less than 20 million rials & 42 & 42 & 37 & 37 & \multirow[t]{3}{*}{0.178} \\
\hline & 20-40 million rials & 38 & 38 & 40 & 40 & \\
\hline & More than 40 million rials & 20 & 20 & 23 & 23 & \\
\hline \multirow[t]{2}{*}{ Smoking history } & Yes & 17 & 17 & 12 & 12 & \multirow[t]{2}{*}{0.128} \\
\hline & No & 83 & 83 & 88 & 88 & \\
\hline \multirow[t]{2}{*}{ Family history of cardiovasculardiseases } & Yes & 22 & 22 & 18 & 18 & \multirow[t]{2}{*}{0.106} \\
\hline & No & 78 & 78 & 82 & 82 & \\
\hline \multirow[t]{2}{*}{ Occupation } & Housewife & 71 & 71 & 64 & 64 & \multirow[t]{2}{*}{0.218} \\
\hline & Employed & 29 & 29 & 36 & 36 & \\
\hline \multirow{2}{*}{$\begin{array}{l}\text { History of educations related to cardiovas- } \\
\text { cular diseases }\end{array}$} & Yes & 14 & 14 & 12 & 12 & \multirow[t]{2}{*}{0.246} \\
\hline & No & 86 & 86 & 88 & 88 & \\
\hline \multirow[t]{4}{*}{ BMl } & Lean (less than 18.5) & 4 & 4 & 3 & 3 & \multirow[t]{4}{*}{0.209} \\
\hline & Natural (18.5-24.9) & 52 & 52 & 49 & 49 & \\
\hline & Overweight (25-29.9) & 35 & 35 & 38 & 38 & \\
\hline & Obese (more than 30) & 10 & 10 & 9 & 9 & \\
\hline
\end{tabular}


nutritional performance related to the cardiovascular disease before the intervention, but three months after the intervention, compared to the control group, the experimental group showed a significant increase in the mentioned constructs (Table 4).

\section{Discussion}

An educational intervention to promote cardiovascular disease-preventing nutritional behaviors helps to disseminate information, change norms and social values related to cardiovascular risk factors, and awareness of the risk of the disease. The present study aimed to apply the TPB to nutritional behaviors associated with cardiovascular disease in women in Fasa city, Fars province, Iran. In this study, first, a cross-sectional study was conducted to determine the factors affecting nutritional behaviors related to cardiovascular disease in 350 women, whose results showed that attitude, subjective norms, and $\mathrm{PBC}$ predict nutritional behaviors related to cardiovascular disease in women. Also, $41.6 \%$ of the variance of behavior is explained by the constructs of the TPB. In a cross-sectional study conducted by Rezabeigi Davarani et al. on 128 women, attitudes, subjective norms, $\mathrm{PBC}$, and intention predicted $37 \%$ of nutritional behaviors related to cardiovascular disease. $\mathrm{PBC}$ was the strongest predictor of intention [24]. The available evidence suggests that the application of the TPB for examining the power of predicting model in behavioral changes showed that, this model can predict around $20-30 \%$ of the observed variance of health behaviors. Although Ajzen demonstrated the effectiveness of TPB-based interventions in predicting the behavioral changes and found that attitude, subjective norm, and $\mathrm{PBC}$ accounted for a significant amount (20\% to $78 \%)$ of variance in behavioral intention [4042]. On the other hand, the systematic review study results showed that it is possible to facilitate behavior changes especially changes in nutrition with using the TPB [43].

In a qualitative study in which Sabzmakan et al. examined the experiences of patients with cardiovascular risk factors and health workers on the determinants of nutritional behavior, the main problem of the patients was that they were unable to follow a regular diet. The findings of this study showed that patients' nutritional behavior was affected by social support (subjective norms) [44].

In the White et al. study, participants $(\mathrm{N}=184)$ completed questionnaires evaluating the standard TPB measures (attitude, subjective norm, and PBC) and additional voluntary planning to eating foods low in saturated fats. Self-report consumption of low unsaturated fats was assessed 1 month later. The results indicated that attitudes and subjective norms predicted intentions to eat foods low in saturated fats and intentions and PBC. Predicted low food intake in saturated fats directly as well as mediated intentional behavior and $\mathrm{PBC}$ of behavior, suggesting an important role for planning as a post-intentional construct determining healthy eating choices [45].

Table 4 Comparison of mean score of TPB constructs and nutritional performance in the experimental and control groups before and three months after the educational intervention

\begin{tabular}{|c|c|c|c|c|}
\hline Variable & Group & $\begin{array}{l}\text { Before intervention } \\
\text { Mean } \pm \text { SD }\end{array}$ & $\begin{array}{l}\text { After intervention } \\
\text { Mean } \pm \text { SD }\end{array}$ & P-value* \\
\hline \multirow[t]{3}{*}{ Attitude } & Experimental & $24.32 \pm 4.28$ & $42.32 \pm 4.03$ & $<0.001$ \\
\hline & Control & $25.12 \pm 4.26$ & $27.01 \pm 4.11$ & 0.122 \\
\hline & $P$-value $e^{* *}$ & 0.216 & $p<0.001$ & \\
\hline \multirow[t]{3}{*}{ Subjective norms } & Experimental & $14.20 \pm 2.23$ & $25.40 \pm 2.56$ & $<0.001$ \\
\hline & Control & $14.87 \pm 2.36$ & $15.39 \pm 2.35$ & 0.316 \\
\hline & $p$-value & 0.412 & $p<0.001$ & \\
\hline \multirow[t]{3}{*}{ Perceived behavioral control } & Experimental & $18.10 \pm 3.14$ & $33.72 \pm 3.47$ & $<0.001$ \\
\hline & Control & $17.79 \pm 2.52$ & $18.10 \pm 2.41$ & 0.323 \\
\hline & $p$-value & .337 & $p<0.001$ & \\
\hline \multirow[t]{3}{*}{ Intention } & Experimental & $13.37 \pm 2.25$ & $30.13 \pm 2.35$ & $<0.001$ \\
\hline & Control & $14.08 \pm 2.16$ & $15.14 \pm 2.08$ & 0.422 \\
\hline & $p$-value & 0.289 & $p<0.001$ & \\
\hline \multirow[t]{3}{*}{ Nutritional performance } & Experimental & $16.28 \pm 3.56$ & $41.38 \pm 3.47$ & $<0.001$ \\
\hline & Control & $17.07 \pm 3.64$ & $18.15 \pm 3.48$ & 0.265 \\
\hline & $p$-value & 0.269 & $p<0.001$ & \\
\hline
\end{tabular}

*The statistical tests used: Paired t-test

**The statistical tests used: Independent sample t-test 
In Wu's study, the TPB predicted dietary sodium intake in heart failure patients [46]. In a study by Moshki and Torabi on lifestyle-related factors, based on the TPB, the attitude was a significant predictor of healthy eating intention [47]. In a study by Rahimi et al., Health Belief Model (HBM) constructs predicted 20\% of the variance of intention to prevent cardiovascular disease behaviors [48].

In a study by Blanchard et al. on 215 cardiac patients, constructs of TPB predicted $30 \%$ of the variance of intention to exercise [49]. In Mullan et al's study, the TPB predicted $47.6 \%$ of changes in breakfast consumption [50]. Also, in the study of Yarmohammadi et al., the constructs of the theory were a poor predictor $(6 \%)$ for fast food consumption behavior among the students in Isfahan [35]. In the study of Sassen et al., TPB constructs predicted $41 \%$ of the variance of intention to physical activity in patients with cardiovascular risk factors. Attitude, subjective norms, and PBC were the predictors of intention [51]. In a study by Moshki et al., HBM constructs predicted $17.3 \%$ of the variance of cardiovascular disease preventive behaviors [52].

The results of an interventional study indicated the effectiveness of an educational intervention based on the TPB in promoting nutritional behaviors associated with cardiovascular disease in women. The mean score of patients' attitudes toward dietary behaviors related to cardiovascular disease in the experimental group showed a significant increase in the three months after the intervention. Attitude is based on the consequences of one's own experience of behavior or succession experiences through observational learning from others [53]. For this reason, after experiencing a behavior directly, positive beliefs about the consequences of the behavior are reinforced and then as a motivator influence its continuity. Attitude also refers to feelings arising from behavior. The experience of these pleasant emotions can affect their promotion and continuation [54]. The favorable attitude of women towards healthy nutrition is probably due to the availability of educational texts, continuous attendance at educational sessions, the application of brainstorming, discussion on the consequences of healthy eating behavior by target group women, and experiencing positive physical and psychological benefits derived from it.

In a study by Ebrahimi et al., which examined the effect of educational intervention on promoting healthy eating behaviors among students, the results showed that educational intervention caused a positive and incremental change in the knowledge, attitude, and behavior of students in the experimental group on healthy eating [55]. In a clinical trial study conducted by Karimi et al. on 80 patients with myocardial infarction in Bandar Abbas, the experimental group participated in a 4-session educational intervention based on the TPB. The results showed that the attitude, subjective norms, and $\mathrm{PBC}$ increased significantly in the experimental group three months after the intervention [56]. The results of the study by Abbaszadeh et al. showed that educational intervention on patients with myocardial infarction improved their attitudes [57]. In the study of Cespedes et al., the educational intervention improved the knowledge, attitude, habits related to a healthy diet and a healthy lifestyle to prevent cardiovascular disease [58].

In the studies of Jeihooni et al. [59] and Shahmohammadi et al. [60], the educational intervention changed the positive attitude of participants' nutritional behaviors. The mean score of subjective norms showed a significant increase in the experimental group three months after the intervention in comparison with the control group. Holding an educational session using role-playing, group discussion, and question \& answer (Q\&A) with a cardiologist; and using their opinions, attending a family member in the educational session, and engaging health care staff in the training program as social supporters have an important role in improving the score of subjective norms and application of healthy diet behaviors related to cardiovascular disease. In a quasi-experimental study conducted by Salehi and Heydari on 118 women, the educational intervention was performed in three $45 \mathrm{~min}$ of lectures and Q\&A sessions as well as a slide show for the experimental group. There was also a session with family members to discuss a healthy diet. Three months after the intervention, there was a significant increase in the mean scores of reinforcing factors (subjective norms) and attitudes toward cardiovascular diseaserelated diet behaviors [37]. The study of Azadbakht et al. showed that factors such as parents, friends, peers, and mass media influence dietary selection [61]. In Charkazi et al.s study, mate's lack of encouragement and desire to use liquid oil was the most important barriers to appropriate nutritional performance [62]. In Robinson's study, family, friends, and peers played a key role in the nutritional behaviors of African Americans. Besides, the role of women was reported to be of an important emphasis on the interpersonal process that influences nutritional behaviors, as women are primarily responsible for supplying food and interested in improving their health habits [63].

The story also reports that the social environment including interaction with family, friends, and peers will influence dietary selections through mechanisms such as imitation patterns, social support, and social norms. Therefore, it is suggested that the individuals and families attend the educational classes, as family support can be effective in maintaining a diet [64]. In Kothe and Mullan's 
study, subjective norms related to fruit and vegetable consumption increased after the intervention [65]. In White et al. study, where the effect of educational intervention based on the TPB on promoting physical activity and healthy eating in elderly people with cardiovascular disease and type 2 diabetes were investigated, subjective norms of physical activity in the experimental group, compared to the control group, had a significant increase after the intervention, but there was no significant difference between the two groups in nutrition [66]. Research by Oil et al. highlighted the role of physicians and family support in the prevention of cardiovascular disease [67]. Doo et al. emphasized the role of the family and other subjective norms in nutritional behaviors [68]. In this study, the mean score of $\mathrm{PBC}$ in the experimental group was significantly higher than that of the control group in the three months after the intervention. Educating healthy eating behaviors, providing appropriate nutrition patterns through educational sessions, and providing appropriate encouraging and informative feedback in group discussions led women to an understanding of the benefits and barriers of appropriate nutritional behaviors preventing cardiovascular disease.

PBC means one's perception of to what extent the behavior is under control. If the behavior is not completely under the control of the individual, even when he or she is strongly motivated by subjective norms and attitudes, the behavior may not be due to the interference of circumstances. If people believe that they do not have the resources to perform a behavior, they will probably not have a strong intention to do so. Even though they have a positive attitude toward the behavior or believe that others important to them also endorse the behavior, a sense of control will make them strive to succeed in what they want. As a result, they will adopt the behavior they intend to do [69]. In the study of Rezabeigi Davarani et al., lack of finances, dietary habits, taste, and odor are the most important barriers influencing healthy eating behavior [19]. Folta et al. cited major barriers to women's change in reducing cardiovascular risk factors, lack of support of different tastes, and cultural and economic factors [70]. In Moshki et al.s study, a significant correlation was found between perceived barriers and cardiovascular disease preventive behaviors [52].

In a quasi-experimental study conducted by Didarloo et al., using the TPB to promote obesity preventive lifestyle, three months after educational intervention, mean score of attitude, subjective norms, PBC and the behavior of experimental group showed a significant increase [71]. Hosseini Soorand et al. investigated the effect of an educational program based on the TPB in patients with hypertension. After the intervention, the mean score of PBC, attitude, subjective norm, behavioral intention, and behavior in the experimental group showed a significant increase, but no significant difference was observed in the control group [72]. In a study conducted by Zainali et al. to investigate the effect of educational intervention based on the HBM on promoting preventive behaviors of cardiovascular diseases, after the intervention, the mean score of self-efficacy and preventive behaviors in the experimental group significantly increased and the perceived barriers decreased compared to the control group [38].

In a quasi-experimental study conducted by Rezabeigi Davarani et al. on 128 healthy volunteers to examine the effect of educational intervention based on the TPB on nutritional behaviors related to cardiovascular disease, the experimental group received 6 sessions of 90-min of educational intervention. Six weeks after the intervention, the mean score of knowledge, attitude, PBC, subjective norms, and nutritional behaviors increased significantly in the experimental group [73]. Other results were consistent with the findings of this study [74-76].

The results of this study showed that the mean score of intention and nutritional behaviors related to cardiovascular disease in the experimental group compared to the control group showed a significant increase after the intervention. According to the TPB, increasing the mean score of attitude, subjective norms, and PBC in the experimental group three months after the educational intervention increased their behavioral intention and also promoted nutritional behaviors preventing the cardiovascular disease, hence the positive impact of the educational program. The results of Bahadori Monfared et al's study showed that nutrition education and counseling are effective in improving nutritional behavior and correcting malnutrition behaviors [77].

In the Eqbali Ziyarat et al. study, MEDFICTS (Meats, Eggs, Dairy, Fried Foods, Baked Foods, Convenience Foods Table Fats, and Snacks Dietary Questionnaire) scores improved in patients with myocardial infarction receiving nutritional counseling. It seems that nutritional counseling surgery in patients with myocardial infarction may be effective in reducing the incidence of this disease [78]. The results of Kheiri et al's study showed that mean scores of the HBM constructs and CVD preventive behaviors were significantly increased in the experimental group compared to controls after the intervention [39].

In the interventional study of Zainali et al., 61 patients were included in the study and randomly divided into the intervention and control groups. The intervention group was educated for one month. Three months after the intervention, the mean score of awareness, self-efficacy, guidelines for practice, and preventive behaviors of cardiovascular disease was significantly increased in the 
intervention group compared to the control group. Also, perceived barriers in the intervention group were significantly reduced compared to the control group [38].

The results of Hassani et al's study showed significant differences between the knowledge scores and other items of the TPB model as well as nutritional indices observed in the intervention group after 3 months. Mean serum low-density lipoprotein (LDL) levels were significantly reduced after the intervention. Improvements in serum cholesterol (intragroup) and high-density lipoprotein cholesterol (HDL-C) (intergroup) levels were near the significant post-intervention group [79].

In the study of Karimi et al., the educational intervention based on the Theory of Planning Behavior increased the intention of patients with myocardial infarction (MI) to change their lifestyle in the experimental group [56]. In Wu et al's study, adherence to a low-salt diet in patients with heart failure, the results showed the effect of educational intervention based on the TPB on improving the nutrition of the experimental group [80]. In a study by Welsh et al., which examined the effect of educational intervention based on the TPB on low-salt diet among the patients with heart failure in 2012, the results showed that after 6 months, dietary sodium in the experimental group significantly decreased compared to the control group [81]. The results of other studies were consistent with the results of this study [82-84].

The present study had some limitations the most important of which was conducted only on women and the participants self-reported their nutritional behaviors which may raise the probability of recall and response bias. We decide to resolve it by underlining the confidentiality of during the data gathering process to participants. Also, the similarity of the approach of the present study in males or other groups of individuals is recommended for further studies.

\section{Conclusion}

The results of the present study showed that the educational intervention based on the TPB increased the mean score of attitude, subjective norms, PBC, behavioral intention, and promoted the nutritional behaviors preventing cardiovascular disease in women. Considering the validity of the TPB for influence changing people's beliefs and intentions toward nutrition behavior, therefore this model is recommended to apply and promote a healthy diet among patients with chronic diseases.

\section{Abbreviations}

BMI: Body Mass Index; HBM: Health Belief Model; TPB: Theory of Planned Behavior; PBC: Perceived behavioral control; CVD: Cardiovascular disease; LDL: Low-density lipoprotein; HDL-C: High-density lipoprotein cholesterol.

\section{Acknowledgements}

The present research is a part of the General Medical Student Thesis performed at Fasa University of Medical Sciences. The authors thank and appreciate the financial and spiritual supports of the Research and Technology Deputy of Fasa University of Medical Sciences and also the participation of respectful patients in this research.

\section{Authors' contributions}

AKHJ, HJ, NS, MH, RAM, and PAH conceived and designed the study. AKHJ, NS, $\mathrm{MH}$ analyzed and interpreted the data, and drafted the manuscript. AKHJ, HJ, $\mathrm{NS}, \mathrm{MH}, \mathrm{RAM}$, and PAH were involved in the composition of the study tool, supervision of the research process, and critical revision and review of the manuscript. All the authors read and approved the final manuscript.

\section{Funding}

Not applicable.

\section{Availability of data and materials}

The datasets used and/or analyzed during the current study can be made available by the corresponding author on reasonable request.

\section{Declarations}

\section{Ethics approval and consent to participate}

The study procedures were carried out following the Declaration of Helsinki. This study was approved by the Ethics Committee of Fasa University of Medical Sciences (ethical code IR.FUMS.REC.1397.091). Informed consent was taken from all the participants. For illiterate people involved, informed consent from a parent and/or legal guardian was obtained in the study. There was an emphasis on maintaining privacy in keeping and delivering the information accurately without mentioning the names of the participants. The participants were given the right to leave the interview at any time if they wished to leave the interview process, and they were promised to have the study results if they want.

\section{Consent for publication}

Not applicable.

\section{Competing interests}

The authors declare that they have no competing interests.

\section{Author details}

${ }^{1}$ Nutrition Research Center, Department of Public Health, School of Health, Shiraz University of Medical Sciences, Shiraz, Iran. ${ }^{2}$ Department of Public Health, School of Health and Autism Spectrum Disorders Research Center, Hamedan University of Medical Sciences, Hamedan, Iran. ${ }^{3}$ Departement of Public Health, School of Health, Fasa University of Medical Sciences, Fasa, Iran. ${ }^{4}$ Department of Nursing, School of Nursing, Fasa University of Medical Sciences, Fasa, Iran. ${ }^{5}$ Department of Community Health, Faculty of Medicine \& Health Sciences, Universiti Putra, Selangor, Malaysia. ${ }^{6}$ Department of Public Health, School of Health, Kermanshah University of Medical Sciences, Kermanshah, Iran. ${ }^{7}$ Nutrition Research Center, Department of Public Health, School of Health, Shiraz University of Medical Sciences, Shiraz, Iran.

Received: 18 May 2021 Accepted: 24 November 2021 Published online: 07 December 2021

References

1. Sarrafzadegan N, Mohammmadifard N. Cardiovascular disease in Iran in the last 40 years: prevalence, mortality, morbidity, challenges and strategies for cardiovascular prevention. Arch Iran Med. 2019;22(4):204-10.

2. Shahsavari S, Nazari F, KarimyarJahromi M, Sadeghi M. Epidemiologic study of hospitalized cardiovascular patients in Jahrom hospitals in 2012-2013. Iran J Cardiovasc Nurs. 2013;2(2):14-21.

3. Benjamin EJ, Blaha MJ, Chiuve SE, Cushman M, Das SR, Deo R, et al. Heart disease and stroke statistics - 2017 update: a report from the American Heart Association. Circulation. 2017;135(10):e146-603. 
4. Lozano R, Naghavi M, Foreman K, Lim S, Shibuya K, Aboyans V, et al. Global and regional mortality from 235 causes of death for 20 age groups in 1990 and 2010: a systematic analysis for the Global Burden of Disease Study 2010. Lancet (London, England). 2012;380(9859):2095-128.

5. Barati M, Taheri-Kharameh Z, Farghadani Z, Rásky É. Validity and reliability evaluation of the Persian version of the heart failure-specific health literacy scale. Int J Community Based Nurs Midwifery. 2019;7(3):222-30.

6. Mozaffarian D, Benjamin EJ, Go AS, Arnett DK, Blaha MJ, Cushman M, et al. Executive summary: heart disease and stroke statistics-2016 update: a report from the American Heart Association. Circulation. 2016;133(4):447-54.

7. Heidenreich PA, Trogdon JG, Khavjou OA, Butler J, Dracup K, Ezekowitz $M D$, et al. Forecasting the future of cardiovascular disease in the United States: a policy statement from the American Heart Association. Circulation. 2011;123(8):933-44.

8. Mosca L, Benjamin EJ, Berra K, Bezanson JL, Dolor RJ, Lloyd-Jones DM, et al. Effectiveness-based guidelines for the prevention of cardiovascular disease in women-2011 update: a guideline from the American Heart Association. Circulation. 2011;123(11):1243-62.

9. Members WG, Roger VL, Go AS, Lloyd-Jones DM, Adams RJ, Berry JD, et al. Executive summary: heart disease and stroke statistics—2011 update: a report from the American Heart Association. Circulation. 2011;123(4):459-63

10. Barati M, Darabi D, Moghimbeigi A, Afsar A. Self-regulation behaviors of hypertension and related factors among hypertensive patients. J Adv Biomed Sci. 2011;1(3):116-22.

11. Bairami S, Fathi Y, Mohammadinasab S, Barati M, Mohammadi Y. Relationship between self-care behaviors and quality of life among hypertensive patients visiting comprehensive health centers in Hamadan. Iran J Educ Community Health. 2017;4(1):20-7.

12. Psaltopoulou T, Hatzis G, Papageorgiou N, Androulakis E, Briasoulis A, Tousoulis D. Socioeconomic status and risk factors for cardiovascular disease: impact of dietary mediators. Hellenic J Cardiol. 2017;58(1):32-42.

13. BaireyMerz CN, Andersen H, Sprague E, Burns A, Keida M, Walsh MN, et al. Knowledge, attitudes, and beliefs regarding cardiovascular disease in women: the Women's Heart Alliance. J Am Coll Cardiol. 2017;70(2):123-32.

14. Farghadani Z, Taheri-Kharameh Z, Amiri-Mehra A, Ghajari H, Barati M. The relationship between health literacy and self-care behaviors among patients with heart failure. HAYAT. 2018;24(2):186-96.

15. Homko CJ, Santamore WP, Zamora L, Shirk G, Gaughan J, Cross R, et al Cardiovascular disease knowledge and risk perception among underserved individuals at increased risk of cardiovascular disease. J Cardiovasc Nurs. 2008;23(4):332-7.

16. Barati M, Bayat F, Asadi ZA, AfshariMoshir F, Afshari M. Relationship between health literacy and self-care behaviors in hypertensive patients. J Educ Community Health. 2020;7(2):89-96.

17. Vandevijvere S, Dominick C, Devi A, Swinburn B. The healthy food environment policy index: findings of an expert panel in New Zealand. Bull World Health Organ. 2015;93:294-302.

18. Misra A, Khurana L. Obesity-related non-communicable diseases: South Asians vs White Caucasians. Int J Obes. 2011;35(2):167-87.

19. Matlabi M, Sharifirad G, Mostavafi F, Mohebi S, Azadbakht L. Factors affecting fish consumption based on structures of health education. Struct Health Educ. 2012;8(4):523-36.

20. Sharma M. Theoretical foundations of health education and health promotion. Burlington: Jones \& Bartlett Learning; 2021.

21. Glanz K, Rimer BK, Viswanath K. Health behavior: theory, research, and practice. Hoboken: Wiley; 2015.

22. Byrne M, Walsh J, Murphy AW. Secondary prevention of coronary heart disease: patient beliefs and health-related behaviour. J Psychosom Res. 2005;58(5):403-15.

23. Jalily M, Barati M, Bashirian S. Using social cognitive theory to determine factors predicting nutritional behaviors in pregnant women visiting health centers in Tabriz. Iran J Educ Community Health. 2015;1(4):11-21.

24. RezabeigiDavarani E, Mahmoodi M, Khanjani N, Fadakar DM. Application of planned behavior theory in predicting factors influencing nutritional behaviors related to cardiovascular diseases among health volunteers in Kerman. J Health. 2018;8(5):518-29.

25. KhaniJeihooni A, Jormand H, Harsini PA. The effect of educational program based on beliefs, subjective norms and perceived behavior control on doing pap-smear test in sample of Iranian women. BMC Womens Health. 2021;21(1):1-10.

26 Ajzen I. The theory of planned behaviour: reactions and reflections. Abingdon: Taylor \& Francis; 2011.

27. Karimi $M$, Jormand $H$, Zangeneh $M$. Factors related with tobacco smoking among college students: the application of the extended theory of planned behavior. J Educ Community Health. 2020;7(2):81-7.

28. Momayyezi M, Fallahzadeh H, Rahaei Z, Akrami F, Hosseini M, Shakhs S. Prediction of food safety behaviors based on the theory of planned behavior in iranian women. J Hum Environ Health Promot. 2020;6(1):24-9.

29. Alami A, TavakolySany SB, Tehrani H, Lael-Monfared E, Hosseini Z, Jafari A. The effect of educational intervention on iron and vitamin D consumption based on the theory of planned behaviour in Iranian adolescent girls: a quasi-experimental study. Int J Health Promot Educ. 2019;57(6):316-31.

30. Alami A, Sany SBT, Lael-Monfared E, Ferns GA, Tatari M, Hosseini Z, et al. Factors that influence dietary behavior toward iron and vitamin D consumption based on the theory of planned behavior in Iranian adolescent girls. Nutr J. 2019;18(1):1-9.

31. Emanuel AS, McCully SN, Gallagher KM, Updegraff JA. Theory of planned behavior explains gender difference in fruit and vegetable consumption. Appetite. 2012;59(3):693-7.

32. Blanchard CM, Fisher J, Sparling PB, Shanks TH, Nehl E, Rhodes RE, et al. Understanding adherence to 5 servings of fruits and vegetables per day: a theory of planned behavior perspective. J Nutr Educ Behav. 2009:41(1):3-10.

33. Gholami S, Mohammadi E, Pourashraf Y, Sayehmiri K. Evaluating the predictors of fruit and vegetable consumption behavior in Ilam based on constructs of developed planned behavior theory. J Neyshabur Univ Med Sci. 2014;2(4):8-18.

34. Seo H, Lee S-K, Nam S. Factors influencing fast food consumption behaviors of middle-school students in Seoul: an application of theory of planned behaviors. Nutr Res Pract. 2011;5(2):169-78.

35. Yarmohammadi P, Azadbakht L. Predictors of fast food consumption among high school students based on the theory of planned behavior. 2011.

36. Vahdani F, Abedini S, Mohseni S, Nikparvar M. Nutritional behaviors of cardiovascular diseases prevention in Women Referred to Health Care Centers in Minab town, 2016. J Prev Med. 2016;3(4):59-66.

37. Salehi L, Haidari F. Efficacy of PRECEDE model in promoting nutritional behaviors in a rural society. Iran J Epidemiol. 2011;6(4):21-7.

38. Zainali M, Asadpour M, Aghamolaei T, EsmaeiliNadimi A, Farshidi H, Ghanbarnejad A. Effect of educational intervention based on health belief model to promote preventive behaviors of cardiovascular disease in people with normal angiographic results. J Prev Med. 2015;1(2):1-12.

39. Kheiri M, Jeihooni AK, Alkamel A, Harsini PA. The effect of educational intervention based on the health belief model on the promotion of cardiovascular disease (CVD) preventive behaviors among subjects referred to health centers in Fasa city (Fars province, Iran). Kontakt. 2019:21(2):206-13.

40. Alhamad $\mathrm{H}$, Donyai P. The validity of the theory of planned behaviour for understanding people's beliefs and intentions toward reusing medicines. Pharmacy. 2021;9(1):58.

41. Ajzen I. The theory of planned behavior. Organ Behav Hum Decis Process. 1991;50(2):179-211.

42. Taylor D, Bury M, Campling N, Carter S, Garfied S, Newbould J, et al. A Review of the use of the Health Belief Model (HBM), the Theory of Reasoned Action (TRA), the Theory of Planned Behaviour (TPB) and the Trans-Theoretical Model (TTM) to study and predict health related behaviour change. London: National Institute for Health and Clinical Excellence; 2006. p. 1-215.

43. Horne J, Madill J, O'Connor C, Shelley J, Gilliland J. A systematic review of genetic testing and lifestyle behaviour change: are we using high-quality genetic interventions and considering behaviour change theory? Lifestyle Genom. 2018;11(1):49-63.

44. Morowatisharifabad MA, Mohammadi E. Patients, experiences with cardiovascular disease risk factors and healthcare providers of determinants of the nutritional behavior: a qualitative directed content analysis. Iran J Endocrinol Metab. 2013;15(3):292-302.

45. White KM, Terry DJ, Troup C, Rempel LA, Norman P. Predicting the consumption of foods low in saturated fats among people diagnosed with 
Type 2 diabetes and cardiovascular disease. The role of planning in the theory of planned behaviour. Appetite. 2010;55(2):348-54.

46. Wu J-R, Lennie TA, Dunbar SB, Pressler SJ, Moser DK. Does the theory of planned behavior predict dietary sodium intake in patients with heart failure? West J Nurs Res. 2017;39(4):568-81.

47. Moshki M, Torabi F-S. Lifestyle factors and their association with some relevant factors in adolescence using the theory of planned behavior. $J$ Mazandaran Univ Med Sci. 2014;23(2):117-26.

48. Rahimi T, Shojaei S, Mousavi Miyandashti Z, Jafary Nodoushan Z, Farahabadi M. Predictors of preventive behaviors of cardiovascular diseases: Based on health belief model in women referred to health treatment centers in Qom City, 2014, Iran. 2016.

49. Blanchard CM, Courneya KS, Rodgers WM, Fraser SN, Murray TC, Daub $\mathrm{B}$, et al. Is the theory of planned behavior a useful framework for understanding exercise adherence during phase II cardiac rehabilitation? J Cardiopulm Rehabil Prev. 2003;23(1):29-39.

50. Mullan B, Wong C, Kothe E. Predicting adolescent breakfast consumption in the UK and Australia using an extended theory of planned behaviour. Appetite. 2013;62:127-32.

51. Sassen B, Kok G, Vanhees L. Predictors of healthcare professionals' intention and behaviour to encourage physical activity in patients with cardiovascular risk factors. BMC Public Health. 2011;11(1):1-11.

52. Moshki M, Mojadam M, Dusti IA. Associated factors for preventive behaviors of cardiovascular diseases in employees of khuzestan province health center utilizing the health belief model. J Health. 2015;6:367-77.

53. Solhi M, Jormand $\mathrm{H}$, Gohari MR. Application of media literacy education for changing attitudes about self-medication of slimming supplements. Med J Islam Repub Iran. 2017;31:119.

54. Kashfi SM, KhaniJeihooni A, Rezaeianzade A. Effect of health workers' training programs on preventive behavior of leishmaniosis based on BASNEF model. J Res Health Sci. 2012;12(2):114-8.

55. Ebrahimi S, Ghofranipour F, Tavousi M. The effect of educational intervention on promoting healthy eating behaviors among primary school students in Kermanshah City. Iran J Educ Community Health. 2016;3(3):17-23.

56. Karimy T, Saffari M, Sanaeinasab H, Khalagi K, Hassan-Abadi M. Impact of educational intervention based on theory of planned behavior on lifestyle change of patients with myocardial infarction. Iran J Health Educ Health Promot. 2016;3(4):370-80.

57. Abbaszadeh A, Borhani F, Asadi N. Effects of health belief model-based video training about risk factors on knowledge and attitude of myocardial infarction patients after discharge. J Res Med Sci. 2011;16(2):195.

58. Céspedes J, Briceño G, Farkouh ME, Vedanthan R, Baxter J, Leal M, et al. Targeting preschool children to promote cardiovascular health: cluster randomized trial. Am J Med. 2013;126(1):27-35.

59. Jeihooni AK, Heidari MS, Harsini PA, Azizinia S. Application of PRECEDE model in education of nutrition and physical activities in obesity and overweight female high school students. Obesity Med. 2019;14:100092.

60. Shahmohammadi S, Tavousi M, Ghofranipour F. A comparison of the effectiveness of two training methods of nutritional behavior of elementary school students: opportunistic vs. multimedia training. Iran J Health Educ Health Promot. 2014;2(3):179-85.

61. Azadbakht L, MIRMIRAN P, Moumenan A, Azizi F. Knowledge, attitude and practice of guidance school and high school students in district-i3 of Tehran about healthy diet. 2004

62. Charkazi A, Orouji MA, Hazaveie SM. Investigating of Hydrogenated Vegetable Oils Consumption Based on Precede Model Among Families in Khomein and Mahallat. J Res Dev Nurs Midwifery. 2011;8(1):67-73.

63. Robinson T. Applying the socio-ecological model to improving fruit and vegetable intake among low-income African Americans. J Community Health. 2008;33(6):395-406.

64. Story M, Kaphingst KM, Robinson-O'Brien R, Glanz K. Creating healthy food and eating environments: policy and environmental approaches. Annu Rev Public Health. 2008;29:253-72.

65. Kothe EJ, Mullan BA. A randomised controlled trial of a theory of planned behaviour to increase fruit and vegetable consumption. Fresh Facts Appetite. 2014;78:68-75.

66. White KM, Terry DJ, Troup C, Rempel LA, Norman P, Mummery K, et al. An extended theory of planned behavior intervention for older adults with type 2 diabetes and cardiovascular disease. J Aging Phys Act. 2012:20(3):281-99.
67. Oli N, Vaidya A, Subedi M, Krettek A. Experiences and perceptions about cause and prevention of cardiovascular disease among people with cardiometabolic conditions: findings of in-depth interviews from a periurban Nepalese community. Glob Health Action. 2014;7(1):24023.

68. Doo M, Kim Y. Diet management for dyslipidemia. J Korean Med Assoc. 2016;59(5):358-65.

69. KhaniJeihooni A, Kouhpayeh A, Najafi S, Bazrafshan M-R. Application theory of planned behavior on promotion of safe sexual behaviors among drug users. J Subst Use. 2019;24(3):293-9.

70. Folta SC, Goldberg JP, Seguin R, Reed PN, Nelson ME, Lichtenstein AH. Peer reviewed: Factors related to cardiovascular disease risk reduction in midlife and older women: a qualitative study. Prevent Chronic Dis. 2008:5(1):A06.

71. Didarloo A, Sharafkhani N, Gharaaghaji R, Sheikhi S. Application of theory of planned behavior to improve obesity-preventive lifestyle among students: a school-based interventional study. Int J Pediatr. 2017;5(11):6057-67.

72. HoseiniSoorand A, Miri MR, Sharifzadeh G. Effect of curriculum based on theory of planned behavior, on components of theory in patients with hypertension. J Birjand Univ Med Sci. 2015;22(3):199-208.

73. RezabeigiDavarani E, Mahmoodi MR, Khanjani N, Fadakar MM. The effect of educational intervention based on the theory of planned behavior on nutritional behavior with regard to cardiovascular diseases among health volunteers. J Nutr Food Secur. 2019;4(2):93-100.

74. Jeihooni AK, Kashfi SM, Harsini PA. Impact of an educational intervention on breastfeeding behaviour among pregnant women. Br J Midwifery. 2019;27(1):33-42.

75. Jeihooni AK, Darvishi N, Harsini PA. The effect of educational intervention based on the theory of planned behavior on mammography screening in Iranian women. J Cancer Educ. 2020;35(2):264-73.

76. Jeihooni AK, Fereidouni Z, Harsini PA, Kavi E, Haghshenas H, Akbari L. Effect of educational program on lifestyle of myocardial infarction patients in Iranian population. J Clin Diagn Res. 2018;12(9):LC06-LC10.

77. Bahadori-Monfared A, Keramati A-A, Moazzami-Sahzabi J, Mohamadi F, Farsar A-R. The impact of education on nutritional behavior change among clients of Sardar-Jangal Health Center in 2012.

78. EqbaliZiyarat R, Ghiasvandian S, ZakeriMoghadam M, Kazemnejad A. Effect of nutrition counseling on nutritional behavior of patients with myocardial infarction. J Ardabil Univ Med Sci. 2018;17(4):447-55.

79. Hassani B, Araban M, Haghighizadeh MH, Amani R. Improvement of cardiovascular risk factors by applying a modified educational model of planned behavior among the employees of a large petrochemical company. Iran Red Crescent Med J. 2017;19(6):e13550.

80. Wu J-R, Lennie TA, Dunbar SB, Pressler SJ, Moser DK. Predictors of adherence to a low sodium diet using the theory of planned behavior in patients with heart failure. J Cardiac Fail. 2009;15(6):S84.

81. Welsh D, Lennie TA, Marcinek R, Biddle MJ, Abshire D, Bentley B, et al. Lowsodium diet self-management intervention in heart failure: pilot study results. Eur J Cardiovasc Nurs. 2013;12(1):87-95.

82. Jeihooni AK, Kashfi SM, Kooshkghazi SZ, Kashfi SH. Effectiveness of a training program based in PRECEDE model on fruit and vegetable consumption among female students. International Journal of Pediatrics. 2017.

83. Jeihooni AK, Hidarnia A, Kaveh MH, Hajizadeh E, Askari A. Application of the health belief model and social cognitive theory for osteoporosis preventive nutritional behaviors in a sample of Iranian women. Iran J Nurs Midwifery Res. 2016;21(2):131.

84. KhaniJeihooni A, Ghasemi M, Mobaraei AH, Jamshidi H, Afzali HP. The application of PRECEDE model on preventing osteoporosis in women. Clin Nurs Res. 2021;30(3):241-52.

\section{Publisher's Note}

Springer Nature remains neutral with regard to jurisdictional claims in published maps and institutional affiliations. 